\title{
The effect of a low-fat diet on luteal-phase prolactin and oestradiol concentrations and erythrocyte phospholipids in normal premenopausal women
}

\author{
By CHRISTINE M. WILLIAMS AND KAREN MAUNDER \\ Division of Nutrition \& Food Science, Department of Biochemistry, University of Surrey, \\ Guildford GU2 5XH, Surrey \\ AND D. THEALE \\ Department of Clinical Biochemistry and Nutrition, St Luke's Hospital, \\ Guildford GU2 5LX, Surrey
}

(Received 13 June 1988 - Accepted 20 December 1988)

\begin{abstract}
1. Fifteen normal premenopausal women followed a low-fat diet for a period of 2 months.
2. Daily fat intake was reduced from $81 \mathrm{~g}$ on their customary diet to $36 \mathrm{~g}$ on the low-fat diet. A significant reduction in total energy intake and an increase in the dietary polyunsaturated fat: saturated fat ratio was also observed. There was a significant decline in body-weight, percentage body fat and total serum cholesterol, but no significant change in high-density-lipoprotein-cholesterol.

3. Luteal-phase prolactin concentrations were not altered, but there was a significant decline in oestradiol concentrations on the low-fat diet. The proportion of erythrocyte inositol-phospholipid was increased on the low-

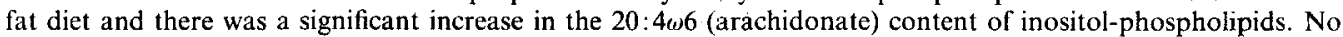
significant changes in the content or fatty acid compositions of other phospholipid fractions were observed.

4. Further investigation of the effect of level and type of dietary fat on the content and fatty acid composition of membrane inositol-phospholipids are required. Long-tern studies investigating the response of both prolactin and oestradiol to dietary fat reduction are also warranted.
\end{abstract}

Epidemiological evidence points to a relation between dietary fat intake and the incidence of, and mortality from, breast cancer in different populations (Lea, 1966; Carroll, 1975; Gray et al. 1979). Feeding studies in animals support such a relation and suggest that not only the amount, but also the type, of fat given may be important (Carroll \& Khor, 1970; Karmali et al. 1984). The mechanisms underlying the relation between dietary fat and breast carcinogenesis are as yet unclear, but recognition of prolactin and oestrogens as strong risk factors in this disease (Moore et al. 1983) has led to the suggestion that dietaryfat-induced alterations in the secretion or metabolism of these hormones, or both, may provide the link between fat intake and propensity towards breast carcinogenesis. Despite this, few studies have been carried out to investigate the effect of alterations in fat intakes on circulating concentrations of oestrogens and prolactin in normal women. Most evidence for modulatory effects of dietary fat on oestrogen and prolactin concentrations are derived from comparative studies of vegetarian and non-vegetarian women (Armstrong et al. 1981; Goldin et al. 1982), in whom intakes of nutrients other than fat may differ. However, the studies of Hill \& Wynder (1976) and Hill et al. (1980), and more recent investigations by Rose et al. $(1987 a, b)$, indicate significant alterations in both oestrogens and prolactin in women undertaking marked changes in their customary fat intakes.

A number of feeding studies in mammary-tumour-bearing animals have shown that alteration in the fatty acid composition of the diet results in marked differences in tumour number and tumour load, and that these differences are associated with significant alteration in tumour membrane phospholipid-fatty acid composition and eicosanoid formation (Rao \& Abraham, 1976; Karmali et al. 1984). These studies lend support to the 
idea that effects of dietary fat on breast cancer are direct, acting via alteration in membrane phospholipid-fatty acid composition and membrane function. We have recently proposed that dietary-induced alterations in mammary membrane inositol-phospholipids may be of particular interest (Williams \& Dickerson, 1987), since this phospholipid has not only been shown to mediate the actions of prolactin on mammary cells (Rillema, 1984), but has also been implicated in the mechanisms which determine abnormal cell division and cell proliferation (Michell, 1984; Nishizuka, 1984). In this way inositol-phospholipids could act as a common locus mediating both direct (membrane), and indirect (hormonal), effects of dietary fat on breast carcinogenesis.

Very few studies have been undertaken to investigate the effect of dietary fat on membrane inositol-phospholipids, although it is generally held that this phospholipid is relatively unresponsive to changes in dietary fat intake. In the present study we have investigated the effect of a low-fat diet on erythrocyte phospholipid composition and on the fatty acid compositions of the choline and inositol fractions in normal, premenopausal women. In addition, measurements of luteal-phase plasma oestradiol and prolactin have been made in subjects on their customary diet and 2 months following a low-fat diet.

\section{SUBJECTS AND METHODS}

Fifteen female subjects aged between 18 and 45 years agreed to follow a low-fat diet for a period of 2 months. All were healthy premenopausal women with regular menstrual cycles, recruited as volunteers from the University of Surrey staff and student population. The study protocol had received consent from the University Ethical Committee. Subjects were selected from a group of volunteers who had completed a questionnaire on menstrual, reproductive and medical history, use of medications and dietary supplements. Subjects were excluded if they were taking oral contraceptives or other hormone preparations, or if they had ceased taking such preparations within the preceding 3 months. Subjects were also excluded if they regularly used dietary supplements containing $\omega 6-$ or $\omega 3$-fatty acids. Other exclusion criteria were an ideal body-weight $<95 \%>120 \%$, or a history of any of the following diseases: diabetes, arthritis, cancer, heart disease, hypertension, alcoholism, thyroid disorders.

The purpose of the study was explained to all volunteers and their consent to participate in the study obtained. A dietary history was taken to ensure that none of the subjects were already following a low-fat diet. All subjects kept records of their menstrual patterns for 2 months before starting the low-fat diet; during this time each subject completed a $7 \mathrm{~d}$ weighed inventory of all food eaten. Detailed instructions for the low-fat diet were not provided until the end of this 2 -month period to preclude pre-emptive adjustment of the subjects' usual diets before obtaining the baseline blood sample. Blood samples $(10 \mathrm{ml})$ were obtained between 08.30 and 09.30 hours after an overnight fast, on a suitable day between days 21 and 26 of the subject's menstrual cycle. Blood samples were collected into heparinized tubes, centrifuged at $3000 \mathrm{~g}$ for $10 \mathrm{~min}$ and plasma and erythrocytes (RBC) separated. Plasma was stored at $-20^{\circ}$ for the later analysis of hormone and lipoprotein concentrations. RBC were washed three times in saline $(9 \mathrm{~g}$ sodium chloride/1), lipids extracted, phospholipids separated and analysed, and the choline and inositol fractions analysed for their fatty acid compositions as indicated later (see p. 653). Subjects were weighed in indoor clothes without shoes; skinfold thickness measurements were determined at four sites (biceps, triceps, subscapula and suprailiac) using a Holtain skinfold caliper. Percentage body fat was calculated using the equation of Durnin \& Rahaman (1967).

Instructions for the low-fat diet were provided at individual interviews. Subjects were asked to consume between 30 and $40 \mathrm{~g}$ fat $/ \mathrm{d}$ and were provided with values for the average 
fat contents of a wide range of commonly eaten foods. Advice was given on the use of cooking methods, choice of foods in restaurants and other locations outside the home, and on the purchase of special low-fat products. Subjects were seen at weekly intervals and compliance to the diet ascertained by $24 \mathrm{~h}$ dietary-recall interviews. Subjects were weighed and skinfold thickness measurements carried out weekly. During the second month of the low-fat diet, subjects carried out a further $7 \mathrm{~d}$ weighed inventory of all food eaten. A second blood sample was taken on a day between days 21 and 26 of the subject's menstrual cycle and samples treated as outlined previously.

\section{Plasma prolactin and oestradiol, total cholesterol and HDL-cholesterol}

Plasma prolactin was determined by a heterologous double-antibody radioimmunoassay (RIA) method in the Department of Clinical Biochemistry and Nutrition, St Luke's Hospital, Guildford. Ampoules of reference preparation were obtained from the RIA Unit, St Bartholomew's Hospital, London and were used as standards. Rabbit anti-prolactin serum was obtained from Guildhay UK Ltd. Iodinated prolactin was supplied by the RIA Unit, St Bartholomew's Hospital. Internal control specimens (low, medium and high) were included at intervals in each assay as well as several carry-over specimens from previous assays.

Plasma oestradiol 17- $\beta$ was determined using a commercially purchased kit (Steranto Research Ltd), which assays oestradiol directly on $50 \mu 1$ plasma samples. All determinations were carried out in duplicate and internal quality-control specimens included at intervals in the batch assay.

Plasma total cholesterol and high-density-lipoprotein (HDL)-cholesterol determinations were carried out using the method of Watson (1960). HDL-cholesterol determinations were carried out on the supernatant fraction from plasma samples pretreated with magnesium chloride to precipitate chylomicron, very-low-density and low-density-lipoprotein fractions.

\section{$R B C$ membrane choline- and inositol-phospholipids}

RBC lipids were extracted using propan-2-ol in place of methanol. This minimizes the extraction of haem-protein which can interfere with the analysis of fatty acids (Broekhuyse, 1974). The packed RBC were washed with saline and lysed with distilled water. Propan-2ol was added, followed by chloroform to extract the lipids. The extract was filtered to remove the cells, washed with $0.05 \mathrm{M}$-potassium chloride and the lower organic phase collected and dried under nitrogen. Separation of individual phospholipid classes was achieved by two-stage thin-layer chromatography. Duplicate 200-400 $\mu 1$ samples were spotted onto $0.25 \mathrm{~mm}$ Silica Gel 60 plates (Merck Ltd) and run initially in a solvent system of hexane-acetone $(75: 25, \mathrm{v} / \mathrm{v})$ to separate neutral lipids and total phospholipids. The plate was then dried and run in a second solvent system of chloroform-methanol-acetic acid-water ( $75: 45: 3: 1$, by vol). This solvent system, a modification of the method of Allan \& Cockcroft (1982), was found to achieve the best separation of serine- and inositolphospholipids. The phospholipid bands were visualized in iodine vapour. Separated bands corresponding to sphingomyelin-, ethanolamine-, choline-, serine- and inositol-phospholipids were removed, the phospholipids hydrolysed, and phosphate determined by the modified method of Bartlett (1959). Bands corresponding to the choline- and inositolphospholipids only, were removed from the other plated sample, the phospholipids hydrolysed and fatty acids methylated and subsequently analysed by gas-liquid chromatography.

Gas-liquid chromatographic analyses were carried out using a Varian 3400 instrument, utilizing a $6 \mathrm{~mm} \times 1.5 \mathrm{~m}$ glass column packed with $10 \mathrm{~g}$ Silar $10 \mathrm{C} / 100 \mathrm{~g}$ Gas Chrom Q 
Table 1. Daily dietary intake of major nutrients by women before and at 2 months after commencing a low-fat dietary regimen $\dagger$

(Mean values and standard deviations for fifteen subjects)

\begin{tabular}{|c|c|c|c|c|}
\hline \multirow[b]{2}{*}{ Dietary intake $(/ d)$} & \multicolumn{2}{|c|}{ Pre-diet } & \multicolumn{2}{|c|}{ Diet for 2 months } \\
\hline & Mean & SD & Mean & SD \\
\hline Energy $(\mathrm{MJ})$ & 7.79 & $1 \cdot 82$ & $6.06^{* * *}$ & 1.72 \\
\hline Fat $(\mathrm{g})$ & 81 & 27 & $36 * * *$ & 19 \\
\hline MUFA (g) & 31 & 9 & $12^{* * *}$ & 5 \\
\hline PUFA $(g)$ & 13 & 4 & 6 & 2 \\
\hline Saturated FA (g) & 35 & 15 & $10^{* * *}$ & 6 \\
\hline $\mathrm{P}: \mathrm{S}$ ratio & 0.38 & $0 \cdot 18$ & $0.61 * *$ & 0.28 \\
\hline Carbohydrate (g) & 221 & 60 & 224 & 80 \\
\hline Protein $(\mathrm{g})$ & 72 & 11 & 67 & 20 \\
\hline Dietary fibre $(\mathrm{g})$ & $22 \cdot 2$ & 6.42 & $27 \cdot 9$ & $10 \cdot 67$ \\
\hline Fat (\% energy) & 37 & 6 & $21 * * *$ & 7 \\
\hline Carbohydrate (\% energy) & 44 & 7 & 56 & 12 \\
\hline Protein (\% energy) & 16 & 3 & 18 & 2 \\
\hline
\end{tabular}

MUFA, monounsaturated fatty acids; PUFA, polyunsaturated fatty acids; FA, fatty acids; P:S, polyunsaturated fat: saturated fat.

Mean values were significantly different from those for the pre-diet period: $* * P<0.01, * * * P<0.001$.

$\dagger$ For details of regimen, see p. 652.

(100-120 mesh). Separated fatty acids were detected using a flame-ionization detector. The initial oven temperature was $165^{\circ}$; this was held for $5 \mathrm{~min}$ and then increased to $215^{\circ}$ at a rate of $5^{\circ} / \mathrm{min}$. The injection temperature was $250^{\circ}$ and detector temperature $275^{\circ}$, with a $\mathrm{N}_{2}$ flow-rate of $30 \mathrm{ml} / \mathrm{min}$. Results for individual fatty acids are expressed as a percentage of total fatty acids. Previous studies had shown precision to be acceptable for all fatty acids comprising $>1 \%$ of total; results for individual fatty acids comprising $<1 \%$ of total have not been presented.

\section{Nutrient composition of weighed dietary intakes}

The daily records of weighed food intake were analysed for their energy and nutrient compositions using the Compeat computer program (Lifeline Nutritional Services Ltd) which uses nutrient composition values from Paul \& Southgate (1978) as a data base. Additional information on the energy and fat contents of specialized low-fat products, not included in the values of Paul \& Southgate (1978), was incorporated into the data base to allow the contribution of these products to total fat intake to be estimated.

\section{Statistical analyses}

Statistical evaluation of changes in the variables measured in subjects after 2 months on the low-fat diet were made by the use of the paired Student's $t$ test. Differences were considered as significant at $P<0.05$.

\section{RESULTS}

Average nutrient intakes of subjects before and at 2 months after commencement of the low-fat diet are shown in Table 1. Fat intakes were reduced by $56 \%$ in subjects changing to the low-fat diet, so that fat intake contributed only $21 \%$ of energy on the low-fat diet compared with $37 \%$ on the high-fat diet. There was a more marked reduction in the intake 
Table 2. Anthropometric measurements on women before and at 2 months following the commencement of a low-fat dietary regimen $\dagger$

(Mean values and standard deviations for fifteen subjects)

\begin{tabular}{|c|c|c|c|c|}
\hline \multirow[b]{2}{*}{ Characteristic } & \multicolumn{2}{|c|}{ Pre-diet } & \multicolumn{2}{|c|}{ Diet for 2 months } \\
\hline & Mean & SD & Mean & So \\
\hline Body-wt $(\mathrm{kg})$ & $64 \cdot 2$ & $9 \cdot 6$ & $61 \cdot 1 * * *$ & $9 \cdot 0$ \\
\hline Skinfold thickness (mm): & & & & \\
\hline Biceps & $12 \cdot 1$ & $5 \cdot 7$ & $8 \cdot 5 * * *$ & $3 \cdot 28$ \\
\hline Triceps & $19 \cdot 2$ & $6 \cdot 2$ & $16 \cdot 5^{* * *}$ & $5 \cdot 36$ \\
\hline Subscapular & $16 \cdot 7$ & $9 \cdot 5$ & $13 \cdot 7^{* * *}$ & 7.9 \\
\hline Suprailiac & $22 \cdot 2$ & $7 \cdot 3$ & $19 \cdot 5^{* * *}$ & $6 \cdot 1$ \\
\hline Body fat $(\mathrm{g} / \mathrm{kg})$ & $32 \cdot 2$ & $5 \cdot 5$ & $29 \cdot 8^{* * *}$ & $5 \cdot 1$ \\
\hline
\end{tabular}

Mean values were significantly different from those for the pre-diet period: ${ }^{* * *} P<0-001$.

$\dagger$ For details of regimen, see p. 652.

Table 3. Luteal-phase serum oestradiol, prolactin and lipid concentrations in women before and 2 months following the commencement of a low-fat dietary regimen $\dagger$

(Mean values and standard deviations for fifteen subjects)

\begin{tabular}{|c|c|c|c|c|}
\hline \multirow[b]{2}{*}{ Serum constituent } & \multicolumn{2}{|c|}{ Pre-diet } & \multicolumn{2}{|c|}{$\begin{array}{c}\text { Diet for } 2 \\
\text { months }\end{array}$} \\
\hline & Mean & SD & Mean & SD \\
\hline Prolactin $(\mu \mathrm{U} / 1)$ & 331 & 237 & 318 & 125 \\
\hline Oestradiol $-17 \beta(\mathrm{pg} / \mathrm{ml})(n 11)$ & 120 & $48 \cdot 9$ & $105^{*}$ & $26 \cdot 5$ \\
\hline Total cholesterol $(\mathrm{mg} / \mathrm{l})$ & 1600 & 300 & $1300^{* *}$ & 290 \\
\hline HDL-cholesterol (mg/l) & 410 & 78 & 430 & 116 \\
\hline
\end{tabular}

HDL-cholesterol, high-density-lipoprotein-cholesterol.

Mean values were significantly different from those for the pre-diet period: ${ }^{*} P<0 \cdot 05,{ }^{*} P<0.005$.

+ For details of regimen, see p. 652 .

of saturated $(65 \%)$ and mono-unsaturated $(64 \%)$ fats than polyunsaturated $(45 \%)$ fats, and this was reflected in a higher polyunsaturated fat: saturated fat $(P: S)$ ratio on the lowfat diet. There was no significant change in carbohydrate or protein intake on the low-fat diet, but carbohydrate made a greater contribution to total energy intake. Fibre intake was higher, but not significantly so, on the low-fat diet. Energy intake was reduced by $28 \%$, and this decreased intake was entirely due to the reduction in total fat intake. Anthropometric measurements shown in Table 2, demonstrate that the reduced energy and fat intakes of subjects on the low-fat diet resulted in a significant loss of body-weight; that much of this weight loss represented loss of body fat is shown by the skinfold thickness and percentage body fat measurements made at the end of the dietary period. Average weight loss was $1.76 \mathrm{~kg}$ and average body fat loss was calculated to be $1.53 \mathrm{~kg}$. The skinfold measurements show that the greatest percentage loss was on the biceps region $(29 \%)$; less marked changes were observed on the triceps $(14 \%)$, subscapular $(17 \%)$ and suprailiac $(12 \%)$ regions.

Measurements of plasma prolactin, oestradiol, total cholesterol and HDL-cholesterol are shown in Table 3 . There was no significant change in the mean prolactin concentration 
Table 4. Relative proportions $(\mathrm{mg} / \mathrm{g}$ ) of erythrocyte phospholipids in women before and at 2 months after commencing a low-fat dietary regimen ${ }^{\dagger}$

(Mean values and standard deviations for thirteen subjects)

\begin{tabular}{|c|c|c|c|c|}
\hline \multirow[b]{2}{*}{ Phospholipid (mg/g) } & \multicolumn{2}{|c|}{ Pre-diet } & \multicolumn{2}{|c|}{ Diet for 2 months } \\
\hline & Mean & SD & Mean & SD \\
\hline Phosphatidylethanolamine & $25 \cdot 4$ & 3.7 & $26 \cdot 6$ & $2 \cdot 3$ \\
\hline Phosphatidylinositol & 60 & 1.5 & $8 \cdot 1^{*}$ & 1.6 \\
\hline Phosphatidylserine & $12 \cdot 6$ & 1.9 & $12 \cdot 0$ & 1.9 \\
\hline Phosphatidylcholine & $30 \cdot 0$ & $4 \cdot 2$ & $28 \cdot 9$ & $3 \cdot 1$ \\
\hline Sphingomyelin & $26 \cdot 0$ & $5 \cdot 6$ & $24 \cdot 7$ & $3 \cdot 3$ \\
\hline
\end{tabular}

Mean values were significantly different from those for the pre-diet period: ${ }^{*} P<0.02$.

$\dagger$ For details of regimen, see p. 652.

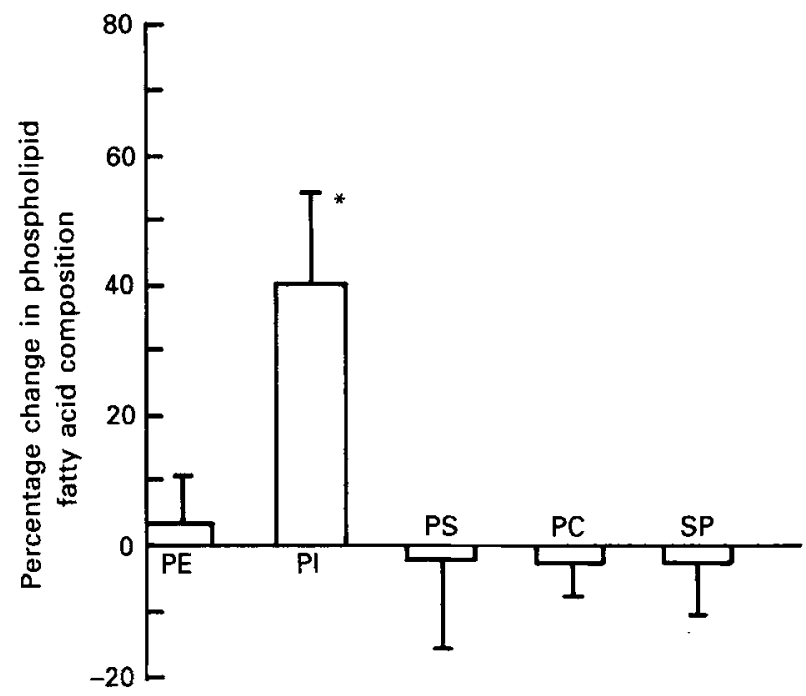

Fig. 1. Percentage change in the relative proportions of erythrocyte phospholipids in women after 2 months on a low-fat diet. Values are means, with their standard errors represented by vertical bars, for thirteen subjects. ${ }^{*} P<0.02$.

PE, phosphatidylethanolamine; PI, phosphatidylinositol; PS, phosphatidylserine; PC, phosphatidylcholine; SP, sphyingomyelin.

in subjects transferring to a low-fat diet, although two subjects in whom prolactin concentrations were elevated above normal on their customary diet showed normal values on the low-fat diet. These individual changes are reflected in the smaller standard deviation around the mean for prolactin concentrations in subjects on the low-fat diet. Luteal-phase oestradiol concentrations were significantly lower following the low-fat diet; in four subjects oestradiol concentrations decreased $100 \%$ on the low-fat diet. There was a significant reduction in total cholesterol on the low-fat diet, but HDL-cholesterol concentrations remained unchanged.

Values for the proportions of individual phospholipid classes of RBC membranes are shown in Table 4. There was a significant increase in the percentage inositol-phospholipid 
Table 5. Fatty acid composition $(\mathrm{mg} / \mathrm{g})$ of erythrocyte choline- and inositol-phospholipids of women before and at 2 months following the commencement of a low-fat dietary regimen $\dagger$

(Mean values and standard deviations for thirteen subjects)

\begin{tabular}{|c|c|c|c|c|c|c|c|c|}
\hline \multirow[b]{3}{*}{ Fatty acid (mg/g) } & \multicolumn{4}{|c|}{ Choline-phospholipid } & \multicolumn{4}{|c|}{ Inositol-phospholipid } \\
\hline & \multicolumn{2}{|c|}{ Pre-diet } & \multicolumn{2}{|c|}{$\begin{array}{l}\text { Diet for } \\
2 \text { months }\end{array}$} & \multicolumn{2}{|c|}{ Pre-diet } & \multicolumn{2}{|c|}{$\begin{array}{c}\text { Diet for } \\
2 \text { months }\end{array}$} \\
\hline & Mean & SD & Mean & SD & Mean & SD & Mean & SD \\
\hline $16: 0$ & $37 \cdot 2$ & $4 \cdot 9$ & $37 \cdot 6$ & $5 \cdot 3$ & 11.9 & $10 \cdot 6$ & 7.6 & $4 \cdot 2$ \\
\hline $16: 1$ & $0 \cdot 3$ & $0 \cdot 6$ & $0 \cdot 3$ & $0 \cdot 4$ & $0 \cdot 7$ & 1.0 & $0 \cdot 3$ & 0.4 \\
\hline $18: 0$ & $12 \cdot 5$ & 4.0 & $10 \cdot 2$ & 1.7 & 41.9 & 8.8 & $43 \cdot 0$ & $10 \cdot 4$ \\
\hline $18: 1$ & $19 \cdot 9$ & 6.9 & $18 \cdot 7$ & 1.8 & 11.8 & $3 \cdot 1$ & $11 \cdot 7$ & 3.5 \\
\hline $18: 2 \omega 6$ & $19 \cdot 0$ & 5.8 & $20 \cdot 9$ & 4.9 & $5 \cdot 7$ & 3.9 & 5.5 & $4 \cdot 3$ \\
\hline $20: 3 \omega 6$ & $1 \cdot 1$ & 0.5 & 1.2 & $1 \cdot 5$ & $1 \cdot 2$ & 0.7 & $1 \cdot 3$ & 0.6 \\
\hline $20: 4 \omega 6$ & $3 \cdot 7$ & $1 \cdot 3$ & 40 & $1 \cdot 5$ & $12 \cdot 3$ & $4 \cdot 1$ & $169^{* *}$ & $4 \cdot 6$ \\
\hline $20: 5{ }_{t b} 6$ & 0.4 & 0.3 & 0.8 & $0 \cdot 6$ & 0.4 & 0.3 & $0 \cdot 4$ & 0.5 \\
\hline $22: 5 * 3$ & $1 \cdot 3$ & 0.5 & $1 \cdot 3$ & 0.9 & $6 \cdot 3$ & $6 \cdot 3$ & 7.0 & $5 \cdot 6$ \\
\hline $22: 5 \omega 6$ & 0.1 & $0 \cdot 2$ & 1.0 & $3 \cdot 1$ & $1 \cdot 4$ & $1 \cdot 1$ & $1 \cdot 5$ & 1.0 \\
\hline $22: 6 \omega 3$ & $3 \cdot 3$ & $3 \cdot 5$ & $3 \cdot 0$ & $3 \cdot 5$ & $3 \cdot 6$ & $4 \cdot 7$ & $2 \cdot 2$ & $4 \cdot 5$ \\
\hline
\end{tabular}

Mean values were significantly different from those for the pre-diet period: ${ }^{* *} P<0.005$.

$\uparrow$ For details of regimen, see p. 652.

content of $\mathrm{RBC}$ in subjects after 2 months on a low-fat diet. Percentage changes in individual phospholipids are shown in Fig. 1, and it can be seen that the inositolphospholipid fraction showed a $40 \%$ increase in subjects on the low-fat diet; no significant changes in other phospholipid fractions were observed.

The individual fatty acid profiles of the RBC choline- and inositol-phospholipids in subjects on their customary diet, and following 2 months on the low-fat diet, are shown in Table 5. There was no significant change in the composition of individual fatty acids in the choline-phospholipids of subjects after 2 months on the low-fat diet. There was a small, but significant, increase in the $\mathrm{C}_{20: 4}$ content of inositol-phospholipids in subjects after 2 months on the low-fat diet. A decrease in the mean value for $\mathrm{C}_{16: 0}$ was also seen, but this difference was not statistically significant.

\section{DISCUSSION}

Our study has shown no significant alteration in luteal-phase prolactin, but a small $(12 \%)$ decrease in oestradiol concentrations in women changing to a low-fat diet for a period of 2 months. Rose et al. $(1987 a, b)$ observed a $50 \%$ reduction in total oestrogens and a $60 \%$ reduction in bioassayable lactogenic hormone (prolactin-growth hormone) in women changing from a diet containing $35 \%$ energy as fat, to one containing $21 \%$ energy as fat for a period of 3 months. However, in their study a significant reduction in total oestrogens (including the oestradiol fraction) was only seen in the third month of their study, and much smaller changes were observed after 2 months on the low-fat diet. The less marked changes observed in subjects in the present study may therefore be due to the shorter period of dietary intervention. Previous studies which have shown higher faecal and lower urinary excretion of oestrogens (Armstrong et al. 1981; Goldin et al. 1982), and lower plasma oestrone and oestradiol concentrations (Shultz \& Leklem, 1983) in vegetarian 
compared with omnivorous women, have attributed these differences to the combined effects of lower fat and higher fibre intakes in the vegetarians. In the present study dietary fibre intake was higher, but not significantly so, in subjects on the low-fat diet. It is, therefore, unlikely that increased consumption of high-fibre foods is responsible for the decrease in oestradiol concentrations.

Our study showed no effect of reduced fat intake on circulating prolactin concentrations. Previous studies have shown that the relation between dietary fat intake and prolactin is complex. Gray et al. (1981) found no significant alteration in plasma prolactin (measured by RIA) in normal premenopausal women undertaking a $50 \%$ reduction in total fat intake for a period of 2 months, results which are entirely comparable with those found in our own study. Schultz et al. (1987) showed no difference in luteal-phase prolactin (measured by RIA) in vegetarians consuming a diet containing $28 \%$ energy as fat compared with nonvegetarians whose diet provided $38 \%$ energy as fat. Conversely, Hill \& Wynder (1976) reported a reduction in nocturnal prolactin concentrations in normal premenopausal women changing to a low-fat vegetarian diet from their customary diet ( $40 \%$ energy as fat), and measured elevated plasma prolactin in black vegetarian South African women when they transferred from their customary diet (15\% energy as fat), to a diet containing $40 \%$ energy as fat (Hill et al. 1980).

In the study of Rose et al. (1987 b), reported previously, serum prolactin was measured by both RIA and bioassay techniques. Lactogenic hormone bioactivity was shown to be higher in women with cystic breast disease compared with control subjects; furthermore in sixteen women with cystic breast disease, a low-fat diet was shown to promote a $60 \%$ reduction in lactogenic hormone bioactivity. In contrast, when growth hormone and prolactin were measured by RIA, no significant differences in hormone concentrations were observed between control and cystic breast disease subjects, and no significant alterations in either prolactin or growth hormone, measured by RIA, were induced by the low-fat diet. It is clear that further investigation of the relations between dietary fat, lactogenic hormone bioactivity and prolactin are required, since elevated lactogenic hormone concentrations have also been observed in women of families at high risk of breast cancer (Love \& Rose, 1985), and in a significant proportion of women with established breast cancer (Emerman et al. 1985).

The reduction in fat intake achieved by subjects in our study was accompanied by a significant decline in total energy intake, and by a mean weight loss of $1.76 \mathrm{~kg}$. The marked decline in total cholesterol concentrations observed in these individuals cannot, therefore, be attributed to the reduction in total fat intake alone, since weight loss itself is known to result in a fall in cholesterol concentrations. In addition, the reduction in total fat intake led to a rise in the P:S ratio from a pre-diet value of 0.38 to a value of 0.61 on the low-fat diet. Nichaman \& Hamm (1987) have recently stated that the cholesterol-lowering effect of low-fat diets is largely due to alteration in the fatty acid composition, and hence $\mathrm{P}: \mathrm{S}$ ratio of the diet. It is interesting to note that in the study of Rose et al. (1987a), although the restrictions of both total fat and energy were of a similar magnitude to those in our study, there was no change in the $\mathrm{P}: \mathrm{S}$ ratio in subjects transferring from their customary diet to the low-fat diet, and in their subjects there was also no change in total cholesterol concentrations over the period of investigation.

RBC-membrane phospholipids and the fatty acid compositions of the choline- and inositol-phospholipid fractions, did not show marked alterations in subjects consuming a low-fat diet for a period of 2 months. Small, but significant changes were, however, seen in both the content and fatty acid composition of the inositol-phospholipid fraction. Most studies of the phospholipid composition of human RBC have not separated the serine- and inositol-phospholipid fractions, although platelet inositol-phospholipid composition has 
been extensively investigated, with values between 2.7 and $11.8 \%$ reported in the literature (Owen et al. 1981; Ahmed \& Holub, 1984; Dougherty et al. 1987). The pre-diet value of $6 \%$ reported here for $\mathrm{RBC}$ inositol-phospholipids is in the same region as values reported for this membrane component in platelets, but higher than two previous reports for RBC inositol-phospholipids (Williams et al. 1966; Rogiers et al. 1980). Following the low-fat diet there was an increase in the inositol-phospholipid component of the RBC membrane; this increase, although small, was consistently found in all subjects, and represented a $40 \%$ increase in the inositol-phospholipid fraction. The functional significance of such a change is not known.

The fatty acid composition of inositol-phospholipids has been fairly well investigated in human platelets in recent years, but few studies have been carried out in other tissues. Rogiers et al. (1980) and Williams et al. (1966) have reported values for the fatty acid composition of RBC inositol-phospholipids, although values for a number of the major fatty acids reported by these authors differ from one another and from the values found in our subjects. The most notable differences in fatty acids compared with our results were for 18:0 which was higher, and 20:4 which was lower than values reported by both these authors. These differences may be attributed to age and sex effects, since the studies of Rogiers et al. (1980) were carried out on children, and that of Williams et al. (1966) on adult male subjects. These between-study differences may also reflect differences in dietary fatty acid intake in subjects in these various studies. A large number of dietary studies and studies using fatty acid supplements have shown it is possible to alter the fatty acid composition of total phospholipids and individual phospholipid fractions of RBC and platelets by dietary means (Seiss et al. 1980; Brox et al. 1981; Goodnight et al. 1981; Sanders \& Roshanai, 1983). In the present study we have investigated the effect of more subtle dietary changes on RBC choline- and inositol-phospholipid fatty acids. No significant changes in the fatty acid composition of choline-phospholipids were observed on the low-fat diet. There was, however, a significant increase in the $20: 4$ content of the inositol-phospholipids on this diet. The mechanism of this change is unclear, since there was no increase in dietary $20: 4$ intake in subjects on the low-fat diet. The increase in $20: 4$ content may be explained by the decreased consumption of saturated fats, which are reported to suppress the conversion of linoleic to arachidonic acid (Holman, 1977).

Our study has shown that consumption of a low-fat diet over a period of 2 months results in an increase in total inositol-phospholipid content and an increase in the $20: 4$ content of inositol-phospholipid fatty acids. Although these changes were small, they occurred in response to relatively minor changes in dietary fatty acid composition, resulting from a marked reduction in total fat intake. Further investigations of the effect of alterations in total fat and the fatty acid composition of the diet on the inositol-phospholipids of various tissues would appear to be warranted. Compared with other phospholipid fractions, the fatty acid composition of the inositol-phospholipid fraction has been reported to be less responsive to changes in the fatty acid composition of the diet (Brox et al. 1981; Ahmed \& Holub, 1984; Galloway et al. 1985). However, animal studies (Weiner \& Sprecher, 1984), and a recent international comparison study (Dougherty et al. 1987), suggest the phosphoinositide fraction may be more responsive to incorporation of $\omega 9$ (e.g. oleic acid) than $\omega 6$ or $\omega 3$ fatty acids, and that failure to detect changes in the fatty acid composition of inositol-phospholipids may be due to the particular type of fatty acid supplements used in most studies to date. In view of the importance of this membrane component in hormone signal transduction, further investigation of dietary-induced changes of this phospholipid, particularly in hormone-dependent tissues such as breast tissue, would be of interest. 


\section{REFERENCES}

Ahmed, K. \& Holub, B. J. (1984). Alteration and recovery of bleeding times, platelet aggregation and fatty acid composition of individual phospholipids in platelets of human subjects receiving a supplement of cod-liver oil. Lipids 19, 617-624.

Allan, D. \& Cockcroft, S. (1982). A modified procedure for thin-layer chromatography of phospholipids. Journal of Lipid Research 23, 1373-1374.

Armstrong, B. K., Brown, J. B., Clarke, H. T., Crooke, D. K., Hahnel, R., Masarei, J. R. \& Ratajczak, T. (1981). Diet and reproductive hormones: a study of vegetarian and non-vegetarian post-menopausal women. Journal of the National Cancer Institute 67, 761-767.

Bartlett, G. R. (1959). Phosphorous assay in column chromatography. Journal of Biological Chemistry 234, 466-468.

Broekhuyse, R. M. (1974). Improved lipid extraction of erythrocytes. Clinica Chimica Acta 51, 341-343.

Brox, J. H., Kille, J. E., Gunnes, S. \& Nordøy, A. (981). The effect of cod liver oil on platelets and vessel walls in man. Thrombosis and Haemostasis 46, 604-611.

Carroll, K. K. (1975). Experimental evidence of dietary factors and hormone-dependent cancers. Cancer Research 35, 3374-3383.

Carroll, K. K. \& Khor, H. T. (1970). Effects of dietary fat and dose level of 7, 12-dimethylbenz( $($ )anthracene on mammary tumor incidence in rats. Cancer Research 30, 2260-2264.

Dougherty, R. M., Galli, C., Ferro-Luzzi, A. \& Iacono, J. M. (1987). Lipid and phospholipid fatty acid composition of plasma, red blood cells and platelets and how they are affected by dietary lipids: a study of normal subjects from Italy, Finland and the USA. American Journal of Clinical Nutrition 45, 443-455.

Durnin, J. V. \& Rahaman, M. M. (1967). The assessment of the amount of fat in the human body from measurements of skinfold thickness. British Journal of Nutrition 21, 681-689.

Emerman, J. T., Leahy, M., Gout, P. W. \& Bruchovsky, N. (1985). Elevated growth hormone levels in sera from breast cancer patients. Hormones and Metabolic Research 17, 421-424.

Galloway, J. H., Cartwright, I. J., Woodcock, B. E., Greaves, M., Russell, G. G. \& Preston, F. E. (1985). Effects of dietary fish oil supplementation on the fatty acid composition of the human platelet membrane: demonstration of selectivity in the incorporation of eicosapentaenoic acid into membrane phospholipid pools. Clinical Science 68, 449-454.

Goldin, B. R., Adlercrentz, H., Gorbach, S. L., Warram, J. H., Dwyer, J. T., Svenson, L. \& Woods, M. N. (1982). Estrogen excretion patterns and plasma levels in vegetarian and omnivorous women. New England Journal of Medicine 307, 1542-1547.

Goodnight, S. H., Harris, W. S. \& Connor, W. E. (1981). The effects of dietary $\omega 3$ fatty acids on platelet composition and function in man. A prospective, controlled study. Blood 58, 880-885.

Gray, G. E., Pike, M. C. \& Hendersen, B. E. (1979). Breast cancer incidence and mortality rates in different countries in relation to known risk factors and dietary practices. British Journal of Cancer 39, 1-7.

Gray, G. E., Pike, M. C. \& Hendersen, B. E. (1981). Dietary fat and plasma prolactin. American Journal of Clinical Nutrition 34, 1160-1162.

Hill, P., Garbaczewski, L., Helman, P., Huskisson, J., Sporangisa, E. \& Wynder, E. L. (1980). Diet, lifestyle and menstrual activity. American Journal of Clinical Nutrition 33, 11982-11988.

Hill, P. \& Wynder, F. (1976). Diet and prolactin release. Lancet ii, 806-807.

Holman, R. T. (1977). Essential fatty acids in human nutrition. Advances in Experimental Medicine and Biology 83, 515-534.

Karmali, R. A., Marsh, J. \& Fuchs, C. (1984). Effect of omega-3 fatty acids on growth of a rat mammary tumor. Journal of the National Cancer Institute 73, 457-461.

Lea, A. J. (1966). Dietary factors associated with death-rates from certain neoplasms in man. Lancet ii, 332-333.

Love, P. R. \& Rose, D. P. (1985). Elevated bioactive prolactin in women at risk for familial breast cancer. European Journal of Cancer and Clinical Oncology 21, 1553-1554.

Michell, R. (1984). Oncogenes and inositol lipids. Nature 308, 770.

Moore, D. H., Moore, D. H. \& Moore, C. T. (1983). Breast carcinoma etiological factors. Advances in Cancer Research 40, 189-253.

Nichaman, M. Z. \& Hamm, P. (1987). Low-fat, high-carbohydrate diets and plasma cholesterol. American Journal of Clinical Nutrition 45, 1155-1160.

Nishizuka, Y. (1984). Turnover of inositol phospholipids and signal transduction. Science 225, 1365-1370.

Owen, J. S., Hutton, R. A., Day, R. C., Bruckdorfer, R. \& McIntyre, N. (1981). Platelet lipid composition and platelet aggregation in human liver disease. Journal of Lipid Research 22, 423-430.

Paul, A. A. \& Southgate, D. A. T. (1978). McCance and Widdowson's 'The Composition of Foods', 4th ed. London: H.M. Stationery Office.

Rao, G. A. \& Abraham, S. (1976). Enhanced growth rate of transplanted mammary adenocarcinoma induced in C3H mice by dietary linoleate. Journal of the National Cancer Institute 56, 43I-432.

Rillema, J. A. (1984). Prolactin-like actions of phospholipase C on RNA and casein synthesis in mouse mammary gland explants. Hormones and Metabolic Research 16, 532-534. 


\section{Low-fat diet, hormones and phospholipids}

Rogiers, V., Crockaeit, R. \& Vis, H. L. (1980). Altered phospholipid composition and changed fatty acid pattern of the various phospholipid fractions of red cell membranes of cystic fibrosis children with pancreatic insufficiency. Clinica Chimica Acta 105, 105-115.

Rose, D. P., Boyar, A. P., Cohen, C. \& Strong, L. E. (1987a). Effect of a low-fat diet on hormone levels in women with cystic breast disease. I. Serum steroids and gonadotropins. Journal of the National Cancer Institute $\mathbf{7 8}$, 623-626.

Rose, D. P., Cohen, L. A., Berke, B. \& Strong, L. E. (1987 b). Effect of a low-fat diet on serum hormone levels in women with cystic breast disease. II. Serum radioimmunoassayable prolactin and growth hormone and bioactive lactogenic hormones. Journal of the National Cancer Institute 78, 627-631.

Sanders, T. A. B. \& Roshanai, F. (1983). The influence of difference types of 13 polyunsaturated fatty acids on blood lipids and platelet function in healthy volunteers. Clinical Science 64, 91-99.

Seiss, W., Scherer, B., Böhlig, B., Roth, P., Kurzman, I. \& Weber, P. C. (1980). Platelet membrane fatty acids, platelet aggregation and thromboxane formation during a mackeral diet. Lancet i, $441-444$.

Shuitz, T. D. \& Leklem, J. E. (1983). Nutrient intake and hormonal status of premenopausal vegetarian seventhday adventists and premenopausal non-vegetarians. Nutrition and Cancer 4, 247-259.

Shultz, T. D., Wilcox, R. B., Spueher, J. M. \& Howie, B. J. (1987). Dietary and hormonal inter-relationships in premenopausal women: evidence for a relationship between dietary nutrients and plasma prolactin levels. American Journal of Clinical Nutrition 46, 905-911.

Watson, D. (1960). A simple method for the determination of serum cholesterol. Clinical Chemistry 5, $637-643$.

Weiner, T.W. \& Sprecher, H. (1984). Arachidonic acid, 5,8,11-eicosatrienoic acid and 5,8,11,14,17eicosapentaenoic acid. Dietary manipulation of the levels of these acids in rat liver and platelet phospholipids and their incorporation into human platelet lipids. Biochimica et Biophysica Acta 792, 293-303.

Williams, C. M. \& Dickerson, J. W. T. (1987). Dietary fat, hormones and breast cancer: the cell membrane as a possible site of interaction of these two risk factors. European Journal of Surgical Oncology 13, 89-104.

Williams, J. H., Kuckmak, M. \& Witter, R. F. (1966). Fatty acids in phospholipids isolated from human red cells. Lipids 1, 391-398. 